\title{
Germination ecology of the perennial Centaurium somedanum, a specialist species of mountain springs
}

\author{
Eduardo Fernández-Pascual ${ }^{1 *}$, Borja Jiménez-Alfaro1, Ana I. García-Torrico, Félix Pérez-García ${ }^{2}$ \\ and Tomás E. Díaz ${ }^{1}$ \\ 1Jardín Botánico Atlántico, Universidad de Oviedo, Avda. del Jardín Botánico 2230, 33394 Gijón/Xixón, Spain; \\ ${ }^{2}$ Departamento de Biología Vegetal, EUIT Agrícola, Universidad Politécnica de Madrid, Spain
}

(Received 20 December 2011; accepted after revision 11 April 2012; first published online 17 May 2012)

\begin{abstract}
To improve understanding of how a rare endemic species of Centaurium adapts to a specialized ecological niche, we studied the germination ecology of the mountain spring specialist, $C$. somedanum, a perennial species restricted to an unusual habitat for this genus. We conducted laboratory experiments with fresh seeds collected from two populations for three consecutive years, to investigate: (1) the effect of temperature and light on germination; (2) the existence of seed dormancy; and (3) inter-population and inter-annual variation in germinability. Germination occurred only in the light and at relatively low temperatures $\left(15-22^{\circ} \mathrm{C}\right)$ with no differences between constant and alternating regimes, and a significant decrease at high temperatures $\left(25^{\circ} \mathrm{C}\right.$ and $30^{\circ} \mathrm{C}$ ). We found non-deep simple morphophysiological dormancy and variation in seed germinability depending on the year of seed collection. C. somedanum diverged from the common germination characteristics of the genus in: (1) its germination at lower temperatures, which contrasts with what is generally expected in wetland species but could be adaptive in the spring habitat; and (2) its morphophysiological dormancy, which we report here for the first time in the genus and which could be an adaptation to its mountain habitat.
\end{abstract}

Keywords: Centaurium, dormancy, endemic, Gentianaceae, germination, springs, wetlands

\section{Introduction}

Centaurium Hill (Gentianaceae), as defined by Mansion (2004), includes c. 27 species of Mediterranean origin

*Correspondence

Fax: + 34985130685

Email: eduardofp@indurot.uniovi.es and Old World distribution. It is comprised of annual, biennial and, rarely, perennial herbs occurring in different habitats of the Mediterranean basin and surrounding areas (Mansion et al., 2005). Because of its wide distribution and pharmacological importance (Jensen and Schripsema, 2002; Sefi et al., 2011), certain aspects of Centaurium germination ecology have been studied in detail. The comparative germination study of Grime et al. (1981) reported germination of the biennial C. erythraea Rafn. over a wide range of temperatures $\left(13-29^{\circ} \mathrm{C}\right)$ and only in light. Thompson and Grime (1983) confirmed the light requirement for the same species and reported that germination was insensitive to temperature fluctuations, while Schat (1983) found very similar germination characteristics in another biennial, C. littorale (D. Turner) Gilmour. More recently, a series of studies focusing on the effects of salinity, manganese and plant growth regulators reported successful germination at $24-25^{\circ} \mathrm{C}$ in light (Mijajlovic et al., 2005; Zivkovic et al., 2007; Todorovic et al., 2008, 2009; Misic et al., 2009) for the same two species as well as for C. maritimum (L.) Fritsch, C. pulchellum (Swartz) Druce, C. spicatum (L.) Fritsch and C. tenuiflorum (Hoffmanns. \& Link) Fritsch, all of them annual or biennial. All these reports also indicated that germination takes place without previous dormancy-breaking treatments, in contrast with the requirement for cold stratification found in other genera of Gentianaceae (Favarger, 1953) and the morphophysiological dormancy reported in Frasera caroliniensis Walt. (Threadgill et al., 1981) and Sabatia angularis (L.) Pursh (Baskin and Baskin, 2005). However, investigating dormancy was not the aim of any of the aforementioned Centaurium references, and they only studied lowland annual/biennial generalist species of broad geographical distribution. It remains to be seen if the same germination patterns apply in perennial Centaurium species, especially in those living in particular habitats departing from those commonly inhabited by the genus. 
The rare C. somedanum M. Laínz shows several divergences from the general Centaurium traits, as it is a perennial chamaephyte and a specialist species of mountain calcareous springs (Jiménez-Alfaro et al., 2005). It is also a narrow endemic species, confined to a small geographical area $\left(210 \mathrm{~km}^{2}\right)$ located in a transitional region between Mediterranean and Oceanic climatic zones in the Cantabrian Mountain Range of north-west Spain (Jiménez-Alfaro et al., 2010). Because of the ecological and geographical uniqueness of C. somedanum, we may expect divergences from the general germination patterns of the annual/ biennial, generalist and widely distributed Centaurium species. For example, temperate wetland species show a preference for relatively high $\left(c .30^{\circ} \mathrm{C}\right)$ or alternating germination temperatures (Grime et al., 1981; Thompson and Grime, 1983; Schütz, 2000). Another possible adaptation of $C$. somedanum could be seed dormancy to avoid the risks of winter germination in a mountain environment (Baskin and Baskin, 1998), although this dormancy could vary among years and populations, as is usually the case in wild species (Andersson and Milberg, 1998; Giménez-Benavides et al., 2005).

In the present study, we investigated the germination ecology of $C$. somedanum as a contribution to understanding germination in Centaurium and the adaptation of rare endemic species to an ecological niche unusual in this genus. Specifically, we wanted to determine: (1) the temperature and light requirements for its germination; (2) the possible existence of physiological and/or morphological dormancy; and (3) the existence of inter-population and interannual variation in seed germinability.

\section{Materials and methods}

\section{Plant material}

Discrete populations of C. somedanum occur from 600 to $1700 \mathrm{~m}$ above sea level (asl) at the edges of calcareous mountain springs. In these habitats, alkaline spring waters $(\mathrm{pH}>7.7)$ flow from aquifers continuously through the year and are relatively cold even in summer (mean day temperature in late summer $=14.1 \pm 0.2^{\circ} \mathrm{C}$; data from 160 measurements covering the entire altitudinal gradient of the species). Depending on the slope and species composition of the spring edges, two habitat types harbour the populations of $C$. somedanum: vertical travertines and flat calcareous fens (Jiménez-Alfaro et al., 2005).

Although little information is available regarding its reproductive biology, $C$. somedanum is assumed to be a facultative outcrosser, like other species in the genus (Brys and Jacquemyn, 2011). Flowering begins in early July, proceeds during summer and ripe seeds are dispersed in September and October (Jiménez-Alfaro et al., 2010). We observed abundant seedlings in the field in August, so we assume that emergence occurs in summer (mean summer temperature $=15^{\circ} \mathrm{C}$, min. $=10^{\circ} \mathrm{C}$, max. $=22^{\circ} \mathrm{C}$ ), after the cold season has ended (mean winter temperature $=4^{\circ} \mathrm{C}$, $\min .=0^{\circ} \mathrm{C}$, max. $=8^{\circ} \mathrm{C}$ ) (data extrapolated from neighbouring climate stations, Spanish National Meteorological Agency). Seed set is relatively high in wild populations, with c. 140 seeds per fruit. The seeds are roughly spherical, extremely small (c. $390 \mu \mathrm{m}$ wide) and show a reticulate pattern which is common in the Centaurium genus (Bouman et al., 2002). Seed mass (c. $20 \mu \mathrm{g}$ ) is also similar to that of other Centaurium species (Royal Botanic Gardens Kew, 2008). The embryo belongs to Martin's dwarf category (Martin, 1946).

For three consecutive years, we harvested fruits from the two largest populations of $C$. somedanum, which are representative of the two associated habitat types and the altitude gradient of the species (Table 1). In both sites, we sampled all individuals bearing ripe fruits (dry and brownish). The fruits spent a 3-week period in our laboratory $\left(\right.$ c. $22^{\circ} \mathrm{C}, 50 \%$ relative humidity) to ensure homogeneous after-ripening. Afterwards, we removed the seeds from the fruits; cleaned them using sieves and by hand sorting, and used them immediately in the experiments.

\section{Embryo measurements}

We sowed seeds from 2009, from both populations, on $1 \%$ distilled water agar in Petri dishes (diameter $6 \mathrm{~cm}$ ) sealed with Parafilm to prevent desiccation (four

Table 1. Description of the two populations included in this study

\begin{tabular}{|c|c|c|c|c|}
\hline $\begin{array}{l}\text { Collection } \\
\text { site }\end{array}$ & $\begin{array}{l}\text { Altitude } \\
(\mathrm{m} \text { asl) }\end{array}$ & $\begin{array}{l}\text { Habitat, mean } \\
\text { annual temperature }\end{array}$ & Coordinates & $\begin{array}{l}\text { Collection } \\
\text { dates }\end{array}$ \\
\hline La Malva & 600 & Travertine, $10.4^{\circ} \mathrm{C}$ & $\begin{array}{l}43^{\circ} 07^{\prime} 05^{\prime \prime} \mathrm{N} \\
06^{\circ} 15^{\prime} 05^{\prime \prime} \mathrm{W}\end{array}$ & $\begin{array}{l}17.09 .2008 \\
24.09 .2009 \\
02.09 .2010\end{array}$ \\
\hline El Valle & 1280 & Flat fen, $8.3^{\circ} \mathrm{C}$ & $\begin{array}{l}43^{\circ} 04^{\prime} 19^{\prime \prime} \mathrm{N} \\
06^{\circ} 11^{\prime} 49^{\prime \prime} \mathrm{W}\end{array}$ & $\begin{array}{l}17.09 .2008 \\
09.10 .2009 \\
02.09 .2010\end{array}$ \\
\hline
\end{tabular}


dishes with 25 seeds each per population) and kept them in continuous darkness for $24 \mathrm{~h}$ at $20^{\circ} \mathrm{C}$. Afterwards, we excised and measured embryos from 15 seeds per population using a dissecting microscope (MZ6, Leica Microsystems GmbH, Wetzlar, Germany) equipped with a micrometer. The remaining seeds were cold stratified for 12 weeks $\left(3^{\circ} \mathrm{C}\right.$, darkness $)$ and then 15 embryos per population were measured. After cold stratification, seeds were incubated in a growth chamber (Grow-S 360, Ing. Climas, Barcelona, Spain) with a $12 / 12 \mathrm{~h}$ photoperiod (c. $20 \mu \mathrm{mol} \mathrm{m}^{-2} \mathrm{~s}^{-1}$ provided by six Philips TLD30W/54-765 cool fluorescent tubes) at $22 / 12^{\circ} \mathrm{C}$, the summer temperature expected to be optimal. We examined them daily and when the seed coat began to split, i.e. when the embryo had reached its critical length for radicle emergence, we measured another 15 embryos per population. To analyse the embryo measurements, we performed a main effects analysis of variance (ANOVA) with stratification/incubation stage and population as fixed effects using SPSS for Windows 15.0.1 (SPSS Inc., Chicago, Illinois, USA).

\section{Germination experiments}

We carried out laboratory germination experiments on $1 \%$ distilled water agar in Petri dishes sealed with Parafilm. For each treatment, we sowed four dishes with 25 seeds each. To assess the effect of incubation temperature on germination, we incubated seeds from 2009, from both populations, in growth chambers under a 12/12 h photoperiod at 22/12, 15, 20, 25 and $30^{\circ} \mathrm{C}$. To take into account the inter-annual variation on seed germinability, we also incubated seeds from 2008 and 2010 at $22 / 12^{\circ} \mathrm{C}$. Finally, to assess the effect of light on germination, we incubated seeds from 2008 at $22 / 12^{\circ} \mathrm{C}$ in continuous darkness (achieved by wrapping the dishes in two layers of aluminium foil). In all cases, we incubated seeds both after $0(=$ fresh, i.e. after 3 weeks of after-ripening in the laboratory) and 12 ( = stratified) weeks of cold stratification in $1 \%$ agar at $3^{\circ} \mathrm{C}$ in darkness, to check for the existence of physiological dormancy. We did not consider warm stratification as it would be ecologically meaningless according to available knowledge on the habitat and dispersion timing of the species.

We counted and discarded germinated seeds three times a week (with the exception of the darkincubated seeds, which we only checked at the end of the experiment). Radicle emergence was the criterion for germination. After 4 weeks, we terminated all germination tests and opened the non-germinated seeds with a scalpel, classifying them as normal, empty or fungus infected. We excluded the empty and infected seeds from the statistical analyses and the calculation of germination percentages (pooling all the dishes, empty seeds $=3 \pm 1 \%$; infected seeds $=3 \pm 1 \%$ ). We analysed the results by fitting main effects Generalized Linear Models (GLM, binomial error distribution, logit link function) with the test conditions as fixed factors, using SPSS.

\section{Results}

\section{Embryo growth}

We found significant differences in embryo length depending on the stage of the stratification/incubation process $(F=279.592 ; P<0.001)$. While after cold stratification embryo length was similar to that of fresh embryos, at the point of radicle emergence embryos had undergone an increase of $86 \%$ in their length (Fig. 1). We did not detect significant differences in embryo growth between the populations $(F=0.029 ; P=0.866)$.

\section{Germination temperature}

Higher seed germination occurred at lower temperatures $\left(15-22^{\circ} \mathrm{C}\right)$ with a marked decrease at warmer temperatures (Fig. 2). No seeds germinated at $30^{\circ} \mathrm{C}$ and only cold-stratified seeds germinated to a low percentage at $25^{\circ} \mathrm{C}$. These two temperature regimes were qualitatively different and thus we did not include them in the statistical analysis, as their lack of variance would alter the GLM procedure. Analysing the results for the other three temperatures, we detected a significant positive effect of cold stratification on germination (Wald's $\chi^{2}=186.720 ; P<0.001$ ) but neither an effect of incubation temperature

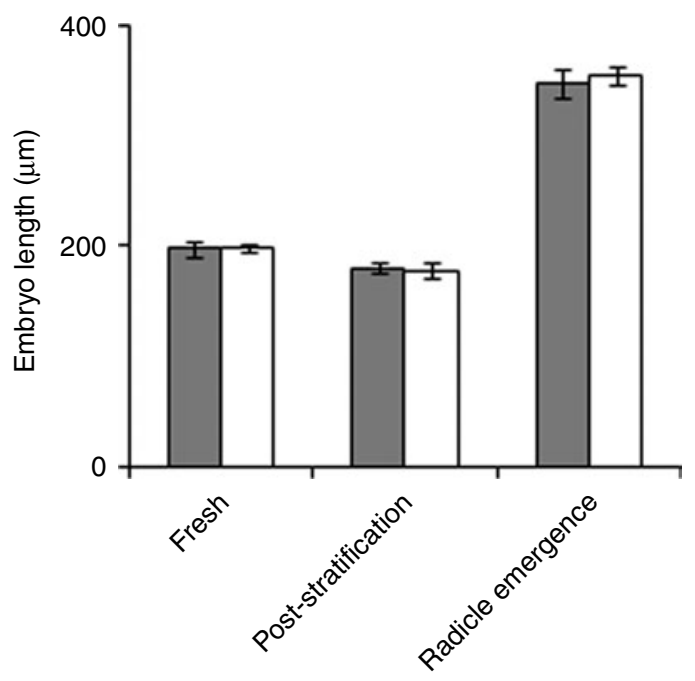

Figure 1. Embryo length $( \pm \mathrm{SE}$ ) in two populations (La Malva, grey bars; El Valle, white bars) at three different stages of the seed stratification-incubation process. 


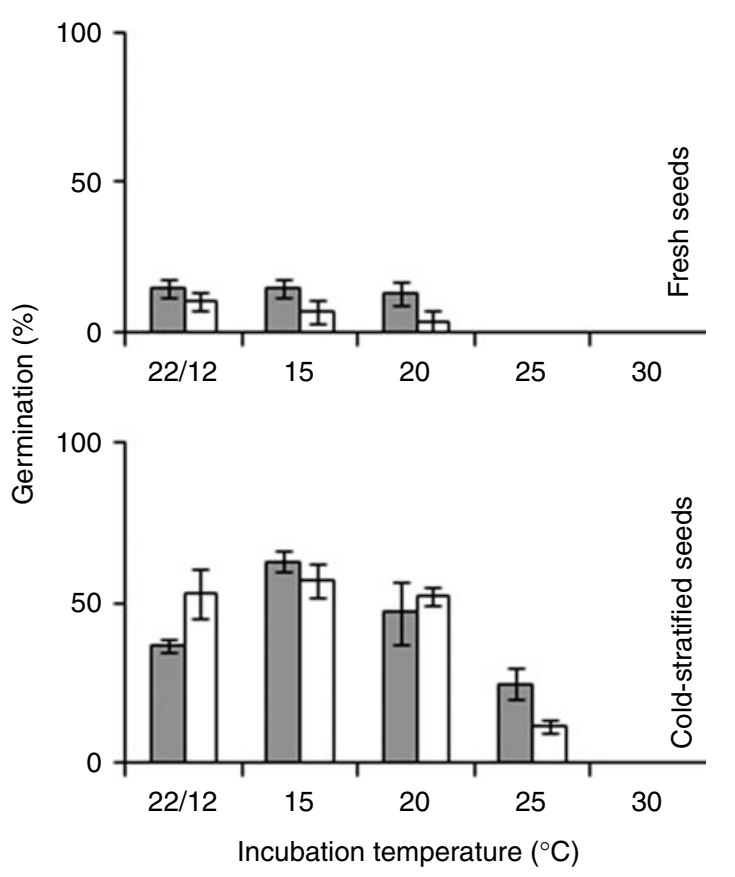

Figure 2. Final germination percentages of fresh (top panel) and stratified (bottom panel) seeds from two populations (La Malva, grey bars; El Valle, white bars) after 4 weeks of incubation at different temperatures. Percentages are the mean \pm SE of four dishes.

(Wald's $\chi^{2}=5.195 ; P=0.074$ ) nor of population (Wald's $\chi^{2}=0.352 ; P=0.553$ ). Thus, in the range most favourable for seed germination, we did not find differences between constant $\left(15,20^{\circ} \mathrm{C}\right)$ and alternating $\left(22 / 12^{\circ} \mathrm{C}\right)$ regimes and no differences between the germination temperature range of seeds from the two populations.

\section{Germinability variation}

We found differences in seed germinability among our collections (Fig. 3). Cold stratification produced a significant germination increase (Wald's $\chi^{2}=222.293$; $P<0.001$ ) across years and populations, but we only obtained almost complete germination in 2008. In the other 2 years, a percentage $(47-80 \%)$ of the seeds did not germinate after 12 weeks of cold stratification. Analysing together all years and populations, we found a significant effect of year (Wald's $\chi^{2}=173.515$; $P<0.001$ ) but not of population (Wald's $\chi^{2}=0.647$; $P=0.421)$.

\section{Effect of light}

Darkness had a clear negative effect on germination. When incubated in darkness, the fresh seeds did not germinate at all, and only $1 \pm 1 \%$ cold-stratified seeds from one population (La Malva) did germinate.
This clear-cut effect of darkness made it impossible, as well as unnecessary, to apply any statistical test.

\section{Discussion}

C. somedanum shows two significant divergences from the previously reported Centaurium germination patterns: (1) a lower germination temperature range; and (2) seed dormancy. Furthermore, its germination requirements are in contrast to the typical responses of wetland species (Grime et al., 1981; Thompson and Grime, 1983; Schütz, 2000) as germination not only occurred at low temperatures, but also showed no increase in response to alternating temperatures. Among the tested conditions, highest germination occurred between 15 and $22^{\circ} \mathrm{C}$. As we did not test colder temperatures, it is not possible to establish the lower temperature limit of the species. In addition, the low germination percentages achieved at $22 / 12^{\circ} \mathrm{C}$ in 2009 and 2010 could indicate that these are suboptimal conditions and that the optimal germination temperature is even lower. However, since the germination of the 2008 stratified seeds was almost complete at $22 / 12^{\circ} \mathrm{C}$, the lower germination found in the following years seems more related to a deeper dormancy in those years, suggesting that the optimal germination temperature should not be too far from the $15-22^{\circ} \mathrm{C}$ range.

In any case, the upper germination temperature limit of C. somedanum is below what was expected. Germination at low temperatures is a common trait of lowland Mediterranean species (Escudero et al., 1997; Doussi and Thanos, 2002), and consequently the temperature requirement for $C$. somedanum germination would seem to be related to the Mediterranean origin of the genus. However, lower germination temperature ranges are usually interpreted as an adaptation to the seasonality of Mediterranean climates that prevents germination during the dry season (Doussi and Thanos, 2002), and this is obviously not the case in the extremely wet environment of $C$. somedanum. The traditional understanding of germination in wetland habitats, as proposed by Thompson and Grime (1983), indicates that the fall of the water table during the spring season produces rising soil temperatures and an increase in diurnal temperature fluctuations. Wetland seeds perceive these signals as marking the optimal season for germination, but the conditions may be very different in mountain spring habitats where water flow is continuous, and even more intense during the spring season when snowmelt recharges aquifers. In our study, seed germination and seedling establishment in C. somedanum take place in the soil of spring edges, where the constantly cold running waters heavily influence the temperature. According to data obtained 

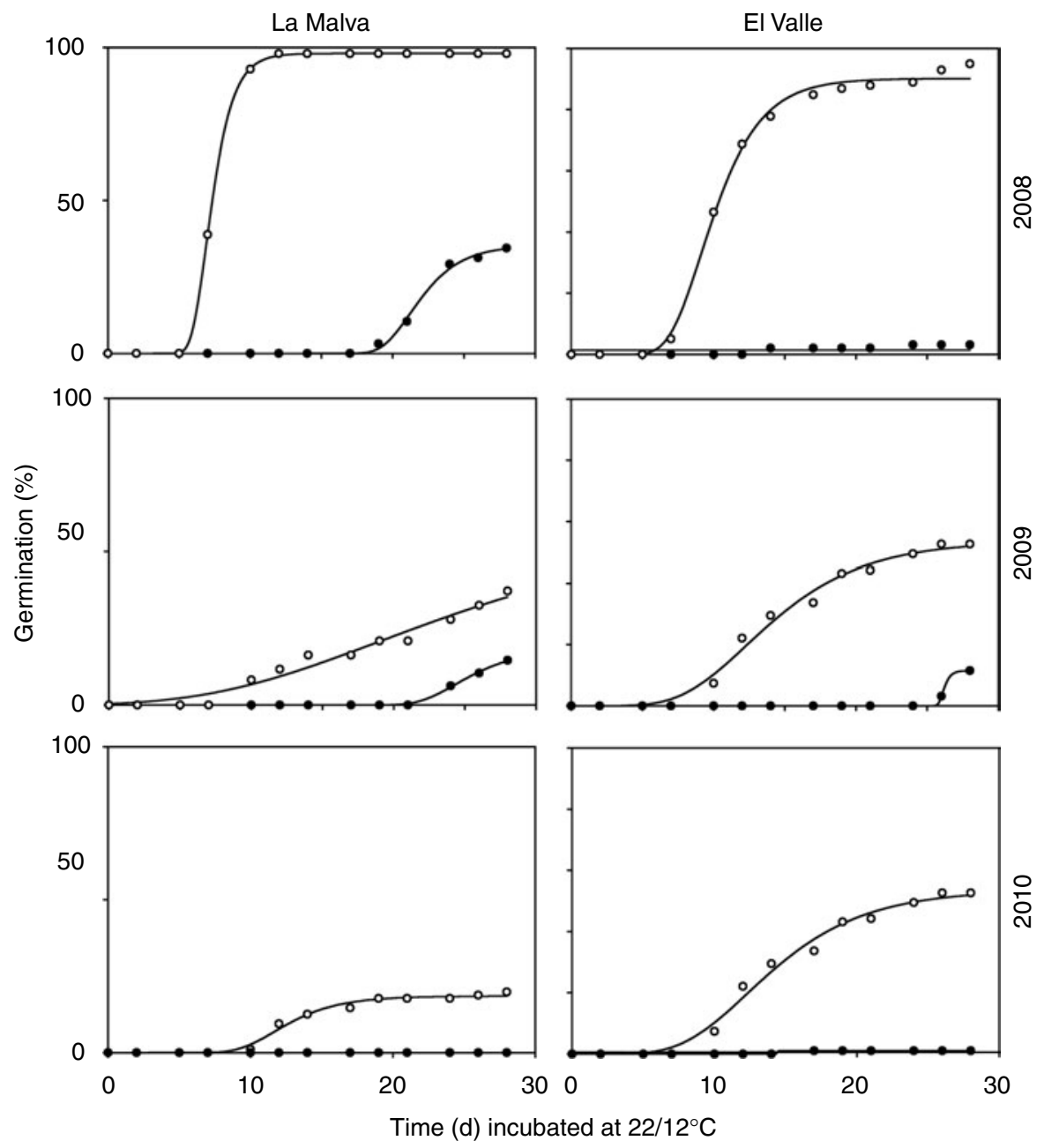

Figure 3. Cumulative germination of fresh (black circles) and stratified (open circles) seeds from each population and year of collection after 4 weeks of incubation at $22 / 12^{\circ} \mathrm{C}$. The lines represent the Gompertz function fitted to the germination data using SigmaPlot 11.0 (Systat Software Inc., San José, California, USA).

by a soil data-logger in La Malva population (M-Log5W, GeoPrecision GmbH, Ettlingen, Germany; data from September 2010 to September 2011), the diurnal thermal amplitude in the soil of the spring edges is relatively low throughout the year $\quad\left(\right.$ winter $=1.9 \pm 0.1^{\circ} \mathrm{C}$, summer $=3.0 \pm 0.1^{\circ} \mathrm{C}$ ) and the summer temperature is considerably less variable than expected $\left(\right.$ mean $=16.9^{\circ} \mathrm{C}$, $\min .=15.7^{\circ} \mathrm{C}$, $\max .=18.8^{\circ} \mathrm{C}$ ). In this environment, germination at low and constant temperatures is probably the only option for the species. However, since we could not establish the lower germination temperature limit, it cannot be excluded that seed germination begins earlier in the year, as from April onwards the soil mean temperature exceeds $10^{\circ} \mathrm{C}$.

The inability of $C$. somedanum to germinate at $25^{\circ} \mathrm{C}$ and above also differs from the successful germination achieved at $25^{\circ} \mathrm{C}$ (Mijajlovic et al., 2005; Zivkovic et al., 2007; Todorovic et al., 2008, 2009) and the $29^{\circ} \mathrm{C}$ upper germination limit found by Grime et al. (1981) in generalist Centaurium species of broad European distribution. It is still necessary to determine whether the lower range in $C$. somedanum is an ancestral Mediterranean character of the genus, which was conserved in this rare endemic and allowed it to colonize the spring habitat; or if it is rather a recent adaptation acquired in the course of such colonization. Although the phylogenetic origin of $C$. somedanum is unclear, the molecular study of Mansion et al. (2005) suggests an allopolyploid origin from the perennial C. scilloides (L. fil.) Samp and the biennial Spanish endemic C. gypsicola (Boiss \& Reut.) Ronniger. C. scilloides is a generalist species widely distributed over the Atlantic coasts of Europe, while C. gypsicola is a specialist species of Mediterranean semi-arid gypsum communities of the central Iberian Peninsula. Thus, investigating the germination response of these species would shed some light on whether the low germination temperature trait of $C$. somedanum has a phylogenetic origin or is a new trait. 
The second divergence from the Centaurium germination pattern regards the seed dormancy we found in the 3 years analysed, contrasting with the non-dormant behaviour reported in the literature for other Centaurium species. Our results show that C. somedanum seeds have non-deep simple morphophysiological dormancy (MPD) according to the classification system of Baskin and Baskin (2004) and that the embryo belongs to the underdeveloped linear embryo category proposed by Baskin and Baskin (2007). Fresh seeds have a non-deep physiological dormancy (PD) which prevents embryo growth and which is overcome by a period of cold stratification. As we did not test warm stratification, it is not possible to determine if cold is a requirement per se, but in nature this dormancy release takes place during the cold winter season. Once the PD is broken, embryo growth must take place before the seed germinates (morphological dormancy, MD). Since embryo growth did not occur during cold stratification, but did occur at warmer temperatures after the seeds were moved to $22 / 12^{\circ} \mathrm{C}$, they have non-deep simple MPD. To our knowledge, this is the first time that MPD has been found in the Centaurium genus, although it has been reported in New World Gentianaceae genera (Threadgill et al., 1981; Baskin and Baskin, 2005). As we have already explained, the thermal regime in the spring habitat is stable during the year in comparison to other, more seasonal, wetland environments. In this context, seed dormancy becomes of foremost importance to ensure that germination takes place in the correct period of the year, i.e. after the colder months of winter.

It is interesting to note that, contrary to what happened with the temperature and light requirements, we found a relatively large variation among seed collections in their germinability. Such variation, depending on year and population, is a well-known phenomenon (Andersson and Milberg, 1998; Giménez-Benavides et al., 2005), which has been usually related to genetic adaptation to local conditions or to the parental environment effect on seed maturation (Fenner, 1991; Baskin and Baskin, 1998). In our case study, the significant effect of year rather than location suggests that it is the environment in each maturation season that determines seed germinability. Nevertheless, further studies controlling either the seed maturation environment (common garden studies) or the genetic background of the populations are necessary to elucidate the relative contribution of the genotype versus the environment.

Besides the divergences commented on above, C. somedanum germination agrees with previous Centaurium studies regarding the lack of response to alternating temperatures (Thompson and Grime, 1983) and the light requirement for germination (Grime et al., 1981; Schat, 1983). The incapacity to germinate in darkness is a trait generally associated with the ability to form a soil seed bank (Pons, 1991; Milberg, 1994) especially in small seeds (Milberg et al., 2000). Other traits of $C$. somedanum seeds tend to be related to persistence in the soil bank, namely their small size and rounded shape (Thompson et al., 1993; Cerabolini et al., 2003). Thus, it is possible that $C$. somedanum forms a persistent soil seed bank, as has been reported for other Centaurium species (Thompson et al., 1997).

In conclusion, our study shows that a rare perennial species of Centaurium living in an unusual habitat presents divergences from the general germination patterns of the genus. The lower germination temperature range in C. somedanum could be of adaptive significance in the very particular conditions of mountain springs, where water flow is continuous and relatively cold throughout the year. It would be of great interest to study the germination temperature ranges of those species phylogenetically linked to C. somedanum, i.e. C. scilloides and C. gypsicola, to improve understanding of the evolutionary history of this trait in the genus. Additionally, it remains to be seen if MPD, a possible adaptation to mountain spring habitats, is shared by more Centaurium species, especially those with a similar ecology, such as C. littorale subsp. uliginosum (Waldst. \& Kit.) Melderis, which lives in travertines and calcareous fens of central Europe. Our findings also suggest that the germination traits of species living in temperate mountain springs could differ from those living in other wetland types, although more studies focused on spring specialists are needed to clarify germination ecology in these habitats.

\section{Acknowledgements}

We would like to thank C. Álvarez, R. Álvarez, Á. Bueno, E. Moratón and J.I. Sanzo for their help during seed collection, and C. Baskin and two anonymous reviewers for their insightful comments on the manuscript and the English revision. The Fundación Biodiversidad (Spanish Ministry of the Environment) funded this research through the project Conservación ex situ de plantas amenazadas de máxima prioridad en el norte peninsular: Aster pyrenaeus y Centaurium somedanum. E.F.P. received a PhD grant from the Government of Asturias (Plan de Ciencia, Tecnología e Innovación del Principado de Asturias) and B.J.A. from the European Social Fund through the Spanish Ministry of Science (PTA2007-0726-I).

\section{References}

Andersson, L. and Milberg, P. (1998) Variation in seed dormancy among mother plants, populations and years of seed collection. Seed Science Research 8, 29-38. 
Baskin, C.C. and Baskin, J.M. (1998) Seeds. Ecology, biogeography, and evolution of dormancy and germination. San Diego, Academic Press.

Baskin, C.C. and Baskin, J.M. (2005) Underdeveloped embryos in dwarf seeds and implications for assignment to dormancy class. Seed Science Research 15, 357-360.

Baskin, C.C. and Baskin, J.M. (2007) A revision of Martin's seed classification system, with particular reference to his dwarf-seed type. Seed Science Research 17, 11-20.

Baskin, J.M. and Baskin, C.C. (2004) A classification system for seed dormancy. Seed Science Research 14, 1-16.

Bouman, F., Cobb, L., Devente, N., Goethals, V., Maas, P.J.M. and Smets, E. (2002) The seeds of Gentianaceae. pp. 498-572 in Struwe, L.; Albert, V.A. (Eds) Gentianaceae: systematics and natural history. Cambridge, Cambridge University Press.

Brys, R. and Jacquemyn, H. (2011) Variation in the functioning of autonomous self-pollination, pollinator services and floral traits in three Centaurium species. Annals of Botany 107, 917-925.

Cerabolini, B., Ceriani, R.M., Caccianiga, M., De Andreis, R. and Raimondi, B. (2003) Seed size, shape and persistence in soil: a test on Italian flora from Alps to Mediterranean coasts. Seed Science Research 13, 75-85.

Doussi, M.A. and Thanos, C.A. (2002) Ecophysiology of seed germination in Mediterranean geophytes. 1. Muscari spp. Seed Science Research 12, 193-201.

Escudero, A., Carnes, L.F. and Pérez García, F. (1997) Seed germination of gypsophytes and gypsovags in semi-arid central Spain. Journal of Arid Environments 36, 487-497.

Favarger, C. (1953) Sur la germination des gentianes. Phyton 4, 275-289.

Fenner, M. (1991) The effects of the parent environment on seed germinability. Seed Science Research 1, 75-84.

Giménez-Benavides, L., Escudero, A. and Pérez García, F. (2005) Seed germination of high mountain Mediterranean species: altitudinal, interpopulation and interannual variability. Ecological Research 20, 433-444.

Grime, J.P., Mason, G., Curtis, A.V., Rodman, J., Band, S.R., Mowforth, M.A.G., Neal, A.M. and Shaw, S. (1981) A comparative study of germination characteristics in a local flora. Journal of Ecology 69, 1017-1059.

Jensen, S.R. and Schripsema, J. (2002) Chemotaxonomy and pharmacology of Gentianaceae. pp. 573-631 in Struwe, L.; Albert, V.A. (Eds) Gentianaceae: systematics and natural history. Cambridge, Cambridge University Press.

Jiménez-Alfaro, B., Bueno Sánchez, Á. and Fernández Prieto, J.A. (2005) Ecología y conservación de Centaurium somedanum M. Laínz (Gentianaceae), planta endémica de la Cordillera Cantábrica (España). Pirineos 160, 45-67.

Jiménez-Alfaro, B., Fernández-Pascual, E. and GarcíaTorrico, A.I. (2010) Centaurium somedanum M. Laínz. pp. 100-101 in Bañares, Á.; Blanca, G.; Güemes, J.; Moreno, J.C.; Ortiz, S. (Eds) Atlas y Libro Rojo de la Flora Vascular Amenazada de España, Adenda 2010. Madrid, Dirección General de Conservación de la Naturaleza.

Mansion, G. (2004) A new classification of the polyphyletic genus Centaurium Hill (Chironiinae, Gentianaceae): description of the New World endemic Zeltnera, and reinstatement of Gyrandra Griseb. and Schenkia Griseb. Taxon 53, 719-740.
Mansion, G., Zeltner, L. and Bretagnolle, F. (2005) Phylogenetic patterns and polyploid evolution in the Mediterranean genus Centaurium (Gentianaceae Chironieae). Taxon 54, 931-950.

Martin, A.C. (1946) The comparative internal morphology of seeds. The American Midland Naturalist 36, 513-660.

Mijajlovic, N., Grubisic, D., Giba, Z. and Konjevic, R. (2005) The effect of plant growth regulators on centaury (Centaurium erythraea Rafn.) seed germination. Archives of Biological Sciences 57, 25-28.

Milberg, P. (1994) Germination ecology of the polycarpic grassland perennials Primula veris and Trollius europaeus. Ecography 17, 3-8.

Milberg, P., Andersson, L. and Thompson, K. (2000) Largeseeded species are less dependant on light for germination than small-seeded ones. Seed Science Research 10, 99-104.

Misic, D., Siler, B., Filipovic, B., Popovic, Z., Zivkovic, S., Cvetic, T. and Mijovic, A. (2009) Rapid in vitro selection of salt-tolerant genotypes of the potentially medicinal plant Centaurium maritimum (L.) Fritsch. Archives of Biological Sciences 61, 57-69.

Pons, T.L. (1991) Induction of dark dormancy in seeds: its importance for the seed bank in the soil. Functional Ecology 5, 669-675.

Royal Botanic Gardens Kew (2008) Seed information database (SID), Version 7.1 May 2008. Available at http://data. kew.org/sid/ (accessed November 2011).

Schat, H. (1983) Germination ecology of some dune slack pioneers. Acta Botanica Neerlandica 32, 203-212.

Schütz, W. (2000) Ecology of seed dormancy and germination in sedges (Carex). Perspectives in Plant Ecology, Evolution and Systematics 3, 67-89.

Sefi, M., Fetoui, H., Lachkar, N., Tahraoui, A., Lyoussi, B., Boudawara, T. and Zeghal, N. (2011) Centaurium erythrea (Gentianaceae) leaf extract alleviates streptozotocininduced oxidative stress and beta-cell damage in rat pancreas. Journal of Ethnopharmacology 135, 243-250.

Thompson, K. and Grime, J.P. (1983) A comparative study of germination responses to diurnally-fluctuating temperatures. Journal of Applied Ecology 20, 141-146.

Thompson, K., Band, S.R. and Hodgson, J.G. (1993) Seed size and shape predict persistence in soil. Functional Ecology 7, 236-241.

Thompson, K., Bakker, J. and Bekker, R. (1997) The soil seed banks of North West Europe: methodology, density and longevity. Cambridge, Cambridge University Press.

Threadgill, P.F., Baskin, J.M. and Baskin, C.C. (1981) Dormancy in seeds of Frasera caroliniensis (Gentianaceae). American Journal of Botany 68, 80-86.

Todorovic, S., Giba, Z., Bacic, G., Nikolic, M. and Grubisic, D. (2008) High seed Mn content does not affect germination of in vitro produced Centaurium pulchellum seeds. Environmental and Experimental Botany 64, 322-324.

Todorovic, S., Giba, Z., Simonovic, A., Bozic, D., Banjanac, T. and Grubisic, D. (2009) Manganese effects on in vitro development of lesser centaury [Centaurium pulchellum (SW.) Druce]. Archives of Biological Sciences 61, 279-283.

Zivkovic, S., Devic, M., Filipovic, B., Giba, Z. and Grubisic, D. (2007) Effect of $\mathrm{NaCl}$ on seed germination in some Centaurium Hill. species (Gentianaceae). Archives of Biological Sciences 59, 227-231. 